\section{Characterization of Ti-Beta zeolites and their reactivity for the photocatalytic reduction of $\mathrm{CO}_{2}$ with $\mathrm{H}_{2} \mathrm{O}$}

\section{Keita Ikeue, ${ }^{a}$ Hiromi Yamashita, ${ }^{a}$ Takahiko Takewaki, ${ }^{b}$ Mark E. Davis, ${ }^{b}$ and Masakazu Anpo*a}

a Department of Applied Chemistry, Graduate School of Engineering, Osaka Prefecture University, 1-1 Gakuen-cho, Sakai, Osaka 599-8531, Japan.

E-mail:anpo@ok.chem.osakafu-u.ac.jp

${ }^{b}$ Division of Chemistry and Chemical Engineering, California Institute of Technology, Pasadena, California, 91125, USA.

A characterization of Ti-Beta zeolites synthesized under various conditions as well as an investigation of their photocatalytic properties for the reduction of $\mathrm{CO}_{2}$ with $\mathrm{H}_{2} \mathrm{O}$ at $323 \mathrm{~K}$ to produce $\mathrm{CH}_{4}$ and $\mathrm{CH}_{3} \mathrm{OH}$ were carried out. In situ XAFS spectra measurements indicated that a highly dispersed tetrahedral titanium oxide species was present in the zeolite framework and an increase in the coordination number of the titanium oxide species by the addition of $\mathrm{H}_{2} \mathrm{O}$ and $\mathrm{CO}_{2}$ molecules could be detected. The Ti-Beta zeolite having a hydrophilic property ( Ti$\operatorname{Beta}(\mathrm{OH})$ ) exhibited a more dramatic increase in the coordination number than the Ti-Beta $(\mathrm{F})$ zeolite which had a hydrophobic property. These results suggest that $\mathrm{CO}_{2}$ and $\mathrm{H}_{2} \mathrm{O}$ molecules can be adsorbed efficiently onto the highly dispersed tetrahedrally coordinated titanium oxide species. UV irradiation of these Ti-Beta zeolite catalysts in the presence of $\mathrm{H}_{2} \mathrm{O}$ and $\mathrm{CO}_{2}$ led to the formation of $\mathrm{CH}_{4}$ and $\mathrm{CH}_{3} \mathrm{OH}$. Ti-Beta(OH) exhibited a higher reactivity than $\mathrm{Ti}-\mathrm{Beta}(\mathrm{F})$, while the selectivity for the formation of $\mathrm{CH}_{3} \mathrm{OH}$ on Ti-Beta $(\mathrm{F})$ was higher than that for Ti$\operatorname{Beta}(\mathrm{OH})$. These results indicated that the reactivity and selectivity of the zeolite catalyst can be determined by the hydrophilic and hydrophobic properties of the zeolites.

Keywords: in-situ XAFS, Photocatalyst, Ti-Beta, $\mathrm{CO}_{2}$

\section{Introduction}

The photocatalytic reduction of $\mathrm{CO}_{2}$ with $\mathrm{H}_{2} \mathrm{O}$ is of interest not only as a reaction system utilizing artificial photosynthesis but also as a way to use carbon sources for the synthesis of oxygenates and hydrocarbons such as $\mathrm{CH}_{4}$ and $\mathrm{CH}_{3} \mathrm{OH}$. We have previously reported that UV-irradiation of highly dispersed tetrahedrally coordinated titanium oxide photocatalysts led to the highly selective formation of $\mathrm{CH}_{3} \mathrm{OH}$ in the photocatalytic reduction of $\mathrm{CO}_{2}$ with $\mathrm{H}_{2} \mathrm{O}$ as compared to octahedrally coordinated bulk $\mathrm{TiO}_{2}$ photocatalysts (Anpo et. al., 1992; Anpo et. al., 1997; Ikeue et. al., 1999). The incorporation of highly dispersed tetrahedrally coordinated titanium oxide species into zeolite cavities which are known to have unique properties made it possible to achieve a more active and selective photocatalytic system. It was recently reported that Ti-containing zeolites, especially the Ti-Beta zeolite synthesized using $\mathrm{OH}^{-}$ions and $\mathrm{F}^{-}$ ions as the counter anions of the structure directing agent, exhibited hydrophilic and hydrophobic properties, respectively (Blasco et. al, 1998).

In the present study, two different Ti-Beta zeolites having hydrophilic and hydrophobic properties were synthesized and the photocatalytic reduction of $\mathrm{CO}_{2}$ with $\mathrm{H}_{2} \mathrm{O}$ to produce $\mathrm{CH}_{4}$ and $\mathrm{CH}_{3} \mathrm{OH}$ was carried out as the photocatalytic reaction. The effect of these properties of zeolites and the local structure of the titanium oxide species incorporated into the zeolite frameworks on the reactivity and selectivity for their photocatalytic reactions have been investigated.

\section{Experimental section}

The Ti-Beta zeolites were synthesized under hydrothermal conditions using two kinds of structure directing agents (SDA) from material mixtures with the compositions expressed below: Two different Ti-Beta will be denoted according to the kind of counter anion of the SDA, i. e., Ti-Beta $(\mathrm{OH})$ and Ti-Beta(F).

Ti-Beta(OH); $1 \mathrm{SiO}_{2}: 0.02 \mathrm{TiO}_{2}: 0.2 \mathrm{SDA}\left(\mathrm{OH}^{-}\right): 30 \mathrm{H}_{2} \mathrm{O}$
Ti-Beta(F); $1 \mathrm{SiO}_{2}: 0.02 \mathrm{TiO}_{2}: 0.56 \mathrm{SDA}\left(\mathrm{F}^{-}\right): 7 \mathrm{H}_{2} \mathrm{O}$

$\operatorname{SDA}\left(\mathrm{OH}^{-}\right)$and $\operatorname{SDA}\left(\mathrm{F}^{-}\right)$were $\mathrm{N}, \mathrm{N}^{\prime}$-dibenzyl-4, 4'-trimethylene bis(N-methylpiperidinium)dihydroxide and tetraethylammonium fluoride (TEAF), respectively. The products were washed with distilled water and dried in air at $353 \mathrm{~K}$. To remove the occluded organic molecules, the samples were heated under a flow of dry air at $823 \mathrm{~K}$ for $4 \mathrm{~h}$.

The photocatalytic reduction of $\mathrm{CO}_{2}$ with $\mathrm{H}_{2} \mathrm{O}$ was carried out with the catalysts $(50 \mathrm{mg})$ in a quartz cell with a flat bottom (88 $\left.\mathrm{cm}^{3}\right)$ connected to a conventional vacuum system $\left(10^{-4}\right.$ Pa range). Prior to the photoreactions and spectroscopic measurements, the catalysts were heated in $\mathrm{O}_{2}$ at $725 \mathrm{~K}$ and evacuated at $475 \mathrm{~K}$ to $10^{-4} \mathrm{~Pa}$. UV-irradiation of the catalysts in the presence of $\mathrm{CO}_{2}$ $(36 \mu \mathrm{mol})$ and gaseous $\mathrm{H}_{2} \mathrm{O}(120 \mu \mathrm{mol})$ was carried out using a $75-\mathrm{W}$ high pressure $\mathrm{Hg}$ lamp $(\lambda>250 \mathrm{~nm})$ at $323 \mathrm{~K}$. The reaction products collected in the gas phase were analyzed by gas chromatography.

The photoluminescence spectra of the catalysts were measured at $298 \mathrm{~K}$ and $77 \mathrm{~K}$ using a SPEX FLUOLOG-3 spectrophotofluorometer. The UV-VIS adsorption spectra were measured at $298 \mathrm{~K}$ by a Shimadzu UV-2200A spectrophotometer. The XAFS spectra (XANES and EXAFS) of the catalysts were measured at the BL-7C facility of the Photon Factory at the National Laboratory for High-Energy Physics, Tsukuba. The X-ray source was monochromatized using a Si(111) monochromater. Ti K-edge absorption spectra were recorded in the fluorescence mode at $295 \mathrm{~K}$. Fourier transformation was performed on $k^{3}$-weighted EXAFS oscillations in the range of $3-10 \AA^{-1}$. The zeolite samples, obtained as thin self-supporting pellets $(50 \mathrm{mg})$, were placed inside a Pyrex sample cell.

\section{Results and discussion}

In the diffuse reflectance UV-VIS absorption spectra, both the Ti-Beta $(\mathrm{OH})$ and Ti-Beta $(\mathrm{F})$ catalysts exhibited an absorption band in the wavelength region of $200-260 \mathrm{~nm}$, attributed to the LMCT (ligand-to-metal charge transfer) band of the highly dispersed tetrahedrally coordinated titanium oxide species (Marchese et. al., 1998).

Figure 1 shows the Ti K-edge XAFS (XANES and EXAFS) spectra of Ti-Beta(OH) and Ti-Beta(F). In the tetrahedral symmetry, one intense preedge peak corresponding to the dipolar-allowed transition from the $1 \mathrm{~s}$ to $t_{2}$ molecular levels built from the $3 \mathrm{~d}$ and $4 \mathrm{p}$ metal orbital and from the neighboring orbital could be observed (Babonneau et. al., 1988). As shown in Fig. 1 (a-c), Ti-Beta( $(\mathrm{OH})$, Ti-Beta(F), and TS-1 all exhibited one intense preedge peak. The local structure of the titanium oxide species of these zeolites were all found to be in tetrahedral coordination.

Figure 1 also shows the FT-EXAFS spectra of the zeolite catalysts. All of the catalysts exhibited a strong peak due to the neighboring oxygen atoms (a Ti-O bond). These zeolites 
exhibited only a Ti-O peak indicating the presence of the isolated titanium oxide species. From the curve-fitting analysis of the EXAFS spectra, it was found that the tetrahedrally coordinated titanium oxide species consists of four Ti-O bonds having a bond distance of $1.84 \AA$ for Ti-Beta(OH) and $1.83 \AA$ for Ti-Beta(F), respectively. These XAFS and UV-VIS absorption investigations clearly indicate that the local structure of the titanium oxide species of Ti-Beta $(\mathrm{OH})$ and Ti-Beta(F) are highly dispersed and exist in a tetrahedral coordination, and that a difference in the coordination geometry of these species for Ti$\operatorname{Beta}(\mathrm{OH})$ and Ti-Beta(F) could scarcely be observed.
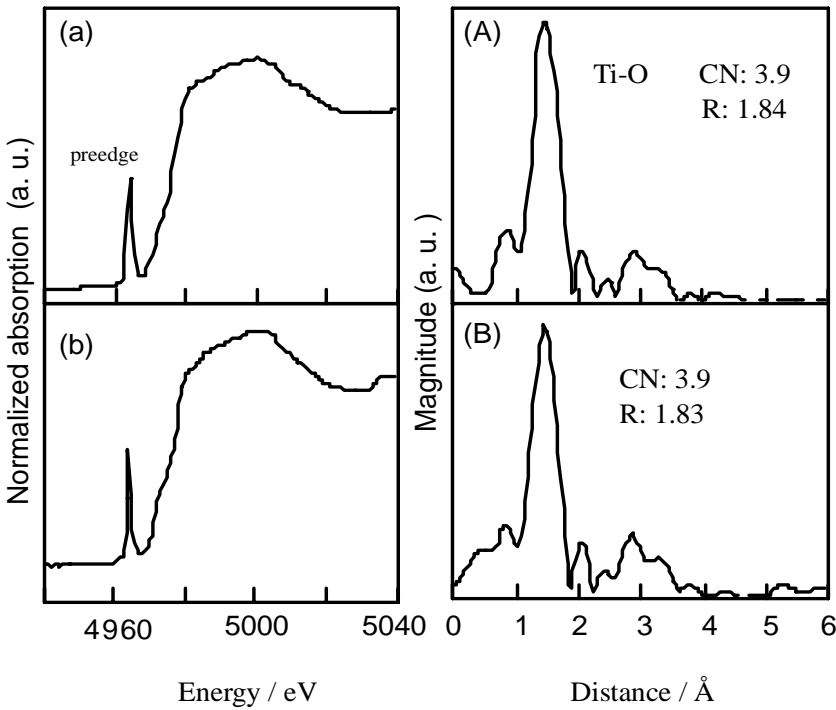

Figure1.

The Ti K-edge XANES $(\mathrm{a}, \mathrm{b})$ and FT-EXAFS $(\mathrm{A}, \mathrm{B})$ spectra of Ti$\operatorname{Beta}(\mathrm{OH})(\mathrm{a}, \mathrm{A})$ and $\mathrm{Ti}-\mathrm{Beta}(\mathrm{F})(\mathrm{b}, \mathrm{B})$. Debye-Waller factors were fixed at $0.003 \AA^{2}$. Coordination number within an error \pm 0.4 . Ti-O bond distance within an error $\pm 0.01 \AA$. $\mathrm{CN}$ : coordination number, R: Ti-O bond distance $(\AA)$

From investigations on the adsorption isotherm of $\mathrm{H}_{2} \mathrm{O}$ at 298 $\mathrm{K}$, it was found that the amount of adsorbed $\mathrm{H}_{2} \mathrm{O}$ molecules on Ti-Beta $(\mathrm{OH})$ was more than those for $\mathrm{Ti}-\mathrm{Beta}(\mathrm{F})$. These results indicated that Ti-Beta( $(\mathrm{OH})$ and Ti-Beta(F) have hydrophilic and hydrophobic properties, respectively. It could, therefore, be expected that the $\mathrm{H}_{2} \mathrm{O}$ molecules are easily accessible to the titanium oxide species on Ti-Beta $(\mathrm{OH})$.

Figure 2 shows the effect of the addition of $\mathrm{H}_{2} \mathrm{O}$ molecules on the preedge peak intensity of the XANES spectra. In both TiBeta zeolites, the addition of $\mathrm{H}_{2} \mathrm{O}$ molecules leads to a decrease in the preedge peak intensity. This decrease was found to be longer for Ti-Beta $(\mathrm{OH})$ than for Ti-Beta $(\mathrm{F})$. Moreover, on Ti$\operatorname{Beta}(\mathrm{OH})$, the position of the preedge peak shifts to a high energy region by the addition of excess amounts of $\mathrm{H}_{2} \mathrm{O}$ molecules (4.6 mmol/g-cat). The shift in the preedge peak position was attributed to a modification in the local geometry of the $\mathrm{Ti}$ atoms from the tetrahedral coordination to a 5 or 6 -fold coordination. On the other hand, the large decrease in the preedge peak intensity and the shift in the position of the preedge peak could not be observed on Ti-Beta(F). These results indicate that $\mathrm{H}_{2} \mathrm{O}$ molecules are easily accessible to the tetrahedrally coordinated titanium oxide species of Ti-Beta $(\mathrm{OH})$, in agreement with the results obtained from the adsorption isotherms of the $\mathrm{H}_{2} \mathrm{O}$ molecules.

UV-irradiation of Ti-Beta zeolite catalysts in the presence of $\mathrm{CO}_{2}$ and $\mathrm{H}_{2} \mathrm{O}$ at $323 \mathrm{~K}$ led to the formation of $\mathrm{CH}_{4}, \mathrm{CH}_{3} \mathrm{OH}$, and trace amounts of $\mathrm{CO}, \mathrm{C}_{2} \mathrm{H}_{4}$, and $\mathrm{O}_{2}$, their yields increasing with the irradiation time. Figure 3 shows the product distribution in the reactions on the catalysts. The Ti-Beta $(\mathrm{OH})$ catalyst exhibits a higher reactivity as compared to the $\mathrm{Ti}-\mathrm{Beta}(\mathrm{F})$ catalyst. On the other hand, the selectivity for the formation of $\mathrm{CH}_{3} \mathrm{OH}$ on Ti$\operatorname{Beta}(\mathrm{F})$ is higher than that for Ti-Beta $(\mathrm{OH})$.

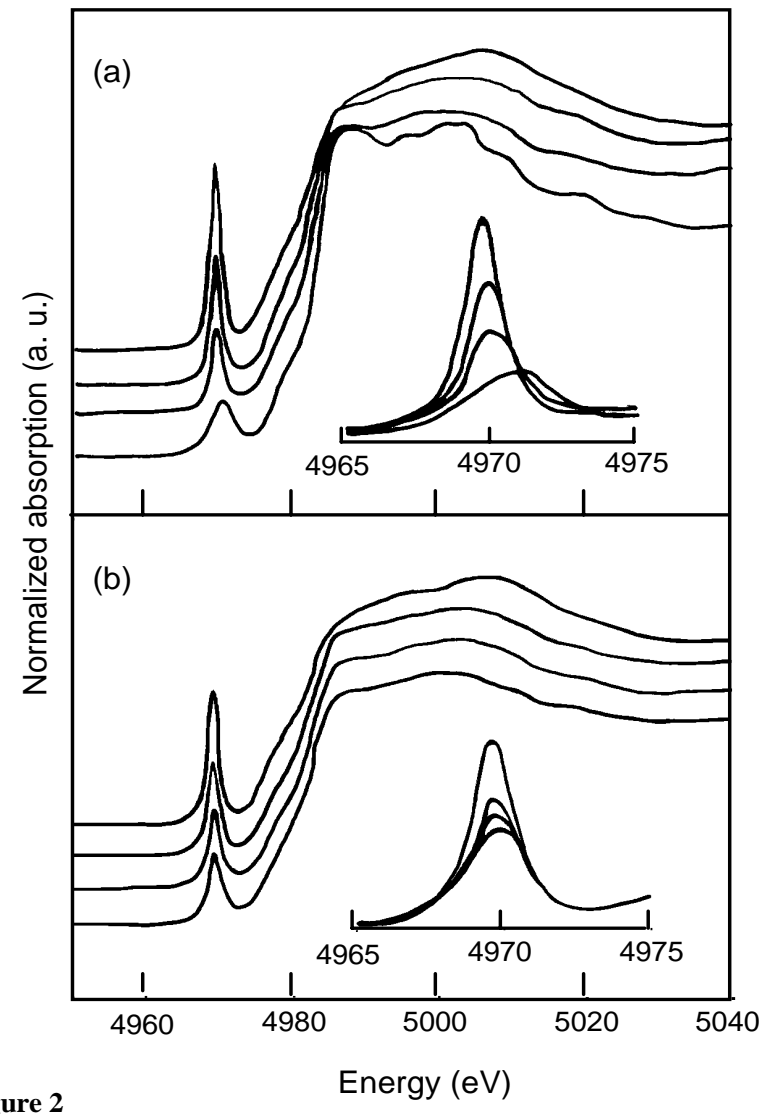

Figure 2

The effect of the addition of $\mathrm{H}_{2} \mathrm{O}$ molecules upon the preedge peak intensity of the XANES spectra. (a) Ti-Beta(OH), (b) Ti-Beta(F). The amount of added $\mathrm{H}_{2} \mathrm{O}$ molecules; $0,1.4,3.0,4.6 \mathrm{mmol} / \mathrm{g}$-cat (from top to bottom).

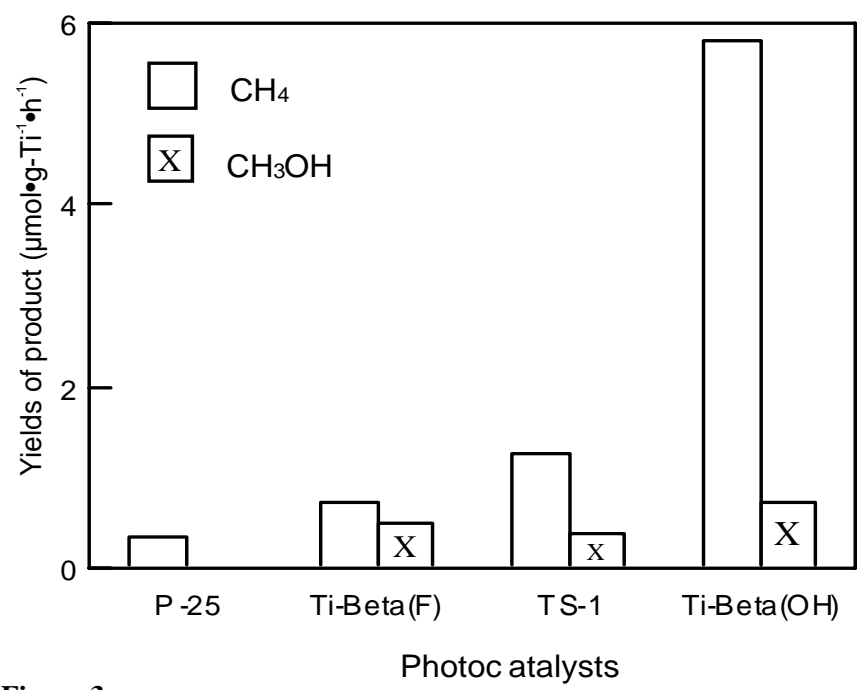

Figure 3

The yields of $\mathrm{CH}_{4}$ and $\mathrm{CH}_{3} \mathrm{OH}$ in the photocatalytic reduction of $\mathrm{CO}_{2}$ with $\mathrm{H}_{2} \mathrm{O}$ at $323 \mathrm{~K}$ on Ti-Beta(OH), TS-1, Ti-Beta(F), and $\mathrm{TiO}_{2}(\mathrm{P}-25)$ as the reference catalyst. 
Ti-Beta $(\mathrm{OH})$ and Ti-Beta(F) both exhibited a photoluminescence spectrum at around $480 \mathrm{~nm}$ by excitation at $260 \mathrm{~nm}$ at $77 \mathrm{~K}$. This spectrum was attributed to the radiative decay process from the charge transfer excited state of the highly dispersed tetrahedrally coordinated titanium oxide species to its ground state. Ti-Beta $(\mathrm{OH})$ exhibit a higher yield of photoluminescence as compared to Ti-Beta $(F)$. The yield of the photoluminescence is related to the number of charge transfer excited complexes $\left(\mathrm{Ti}^{3+}-\mathrm{O}^{-}\right)^{*}$. The higher reactivity of Ti$\operatorname{Beta}(\mathrm{OH})$ over Ti-Beta( $\mathrm{F})$ was attributed to the higher concentration of the charge transfer excited complexes for Ti$\operatorname{Beta}(\mathrm{OH})$.

For Ti-Beta(F) having a hydrophobic property, the relative concentration of $\mathrm{H}_{2} \mathrm{O}$ is much lower than Ti-Beta $(\mathrm{OH})$, resulting in the low reactivity and the high selectivity for the formation of $\mathrm{CH}_{3} \mathrm{OH}$. Thus, the chemical nature, i.e., the hydrophilichydrophobic properties were found to be the deciding factor controlling the reactivity and selectivity in the photocatalytic reduction of $\mathrm{CO}_{2}$ with $\mathrm{H}_{2} \mathrm{O}$ on these zeolite catalysts.

\section{Conclusions}

The characterization of Ti-Beta(OH) and Ti-Beta(F) catalysts by means of XAFS (XANES and FT-EXAFS) and photoluminescence clearly indicated that both catalysts involve highly dispersed tetrahedrally coordinated Ti-oxide species as the major species within zeolite framework. Both Ti-Beta $(\mathrm{OH})$ and Ti-Beta $(F)$ catalysts were found to exhibit high photocatalytic reactivity for the reduction of $\mathrm{CO}_{2}$ with $\mathrm{H}_{2} \mathrm{O}$. The Ti-Beta $(\mathrm{OH})$ catalyst having a hydrophilic property exhibited higher reactivity than Ti-Beta $(\mathrm{F})$ due to the higher concentration of the charge transfer excited complexes $\left(\mathrm{Ti}^{3+}-\mathrm{O}^{-}\right)^{*}$. On the other hand, the highly selective formation of $\mathrm{CH}_{3} \mathrm{OH}$ was observed on the TiBeta(F) catalyst having a hydrophobic property. The change of Ti coordination in the rehydration process indicated that the $\mathrm{H}_{2} \mathrm{O}$ molecules are more easily accessible to the tetrahedrally coordinated titanium oxide species on Ti-Beta $(\mathrm{OH})$ than Ti$\operatorname{Beta}(\mathrm{F})$, attributed to the affinity for the $\mathrm{H}_{2} \mathrm{O}$ molecules for adsorption. The hydrophilic-hydrophobic properties of the zeolite were, therefore, found to be the controlling factor in the reactivity and selectivity for the photocatalytic reduction of $\mathrm{CO}_{2}$ with $\mathrm{H}_{2} \mathrm{O}$ on these zeolite catalysts.

\section{References}

Anpo, M. \& Chiba, K. (1992). J. Mol. Catal. 74, 207-212.

Anpo, M., Yamashita, H., Ichihashi, Y., Fujii, Y. \& Honda, M. (1997). J Phys. Chem. B 101, 2632-2636.

Babonneau, F., Doeuff, S., Leaustic, A., Sanchez, C., Cartier, C. \& Verdaguer, M. (1988). Inorg. Chem. 27, 3166-3172.

Blasco, T., Camblor, M. A., Corma, A., Esteve, P., Guil, J. M., Martínez, Perdigón-Melón, J. A., Valencia, S. (1998). J. Phys. Chem. B 102, 75-88.

Ikeue, K., Yamashita, H. \& Anpo, M. (1999). Chem. Lett. 1135-1136.

Marchese, L., Maschmeyer, T., Gianotti, E., Coluccia, S. \& Thomas J. M. (1997). J. Phys. Chem. B 101, 8836-8838. 